Smith, J. P., and Ngo, K. (2017). "Implementation of Lean Practices Among Finish Contractors in The Us." In: LC3 2017 Volume II - Proceedings of the 25th Annual Conference of the International Group for Lean Construction (IGLC), Walsh, K., Sacks, R., Brilakis, I. (eds.), Heraklion, Greece, pp. 421-428. DOI https://doi.org/10.24928/2017/0182

\title{
IMPLEMENTATION OF LEAN PRACTICES AMONG FINISHING CONTRACTORS IN THE US
}

\author{
James P. Smith ${ }^{1}$ and Khoi Ngo ${ }^{2}$
}

\begin{abstract}
Many parties to the construction process have implemented lean construction practices to improve efficiency within their respective scopes of work. Academics have researched a wide range of these applications in an effort to assess barriers, benefits, and other associated impacts. One area of construction that is currently under-represented in lean literature is finishing contractors. The purpose of this paper was to assess lean implementation by finishing contractors in the US. 33\% of the sample of contractors specializing in the finishing methods reported implementation of some level of lean practices. For those attempting lean, the most common tool being utilized was Last Planner System. The same group reported that implementation was driven by a desire to improve efficiency by cutting costs and reducing schedules. Non-practicing respondents indicated that the primary barrier to implementation was a lack of knowledge in the area.
\end{abstract}

Keywords: Lean construction, finishing contractors, subcontractors, lean implementation

\section{INTRODUCTION}

Lean principles have been successfully implemented by contractors over recent years. Various studies have shown improved efficiency in terms of cost and time as well as other criteria (McGraw Hill 2013). In a relatively comprehensive report, McGraw Hill (2013) stated that $84 \%$ of lean practitioners reported that adopting lean led to higher quality projects, $74 \%$ reported reduced project schedule, and $80 \%$ reported greater customer satisfaction.

In the niche of building finishing, contractors are often smaller and may have limited knowledge and training with lean practices. According to the North American Industry Classification System Association (NAICS) code \#2383, "Building Finishing" contractors includes the following specific trades: drywall, insulation, painting and wall covering, flooring, and finish carpentry. The portion of a construction job that is related to building finishing, especially in the commercial and residential industry, can be relatively time consuming and costly. In the average single family house, the interior finishes cost nearly $30 \%$ of the total construction (Taylor 2014). In the average apartment complex, building finishes average around $12 \%$ of the total project cost (RSMeans 2015).

The application of lean principles in various areas of the construction process has been well-documented in the literature. However, research regarding the implementation of lean practices among building finishing contractors is lacking. The purpose of this research project was to analyze the current level of lean implementation among building

1 Assistant Professor, School of Technology, Department of Construction and Facilities Management, Brigham Young University, Provo, UT, USA, james_smith@byu.edu

2 Masters Degree Student, Department of Construction Science and Management, Clemson University, Clemson, SC, USA, ngominhkhoi@gmail.com 
finishing contractors in the US. More specifically, the following research questions related to building finishing contractors were addressed:

- How common is lean implementation?

- What are the drivers, challenges, benefits and barriers to implementation of lean practices?

This research provides a starting place for analysis of lean implementation in building finishing. It provides a sense of the current state for interested researchers and industry practitioners alike and provides a benchmark of understanding for future work in the area.

\section{LITERATURE REVIEW}

\subsection{Lean Implementation}

Lean construction is a "way to design production systems to minimize waste of materials, time, and effort in order to generate the maximum possible amount of value," (Koskela et al. 2002). The lean philosophy and principles originated in the manufacturing industry but are now commonly used by a variety of industries and trades.

In order to populate the survey with appropriate possible answers, literature describing lean implementation drivers, potential impact areas, common practices, benefits, and barriers and challenges was reviewed. It was determined that the data collected and presented in the report by McGraw Hill (2013) was an appropriate representation of general industry practice and opinion (see also Alarcon et al. 2005; Sarhan and Fox 2012). As such, the majority of potential answers were selected from that report. However, the McGraw Hill report only provided data regarding general contractors and specialty trade contractors (concrete, curtain wall, electrical, glazing/panels, MEP, masonry, roofing, steel erection and fabrication, thermal and moisture control, and vertical transportation. Building finishing contractors were missing from this study.

\subsubsection{Drivers}

McGraw Hill (2013) identified the top drivers for lean construction implementation. This list included 1) client influence, 2) need to increase profitability/cut costs, 3) leadership interest in this area, 4) need to keep up with/ahead of competition, 5) concerns about worker safety, 6) need to decrease project schedule, 7) improved sustainability, and 8) workforce concerns.

\subsubsection{Potential Impact Areas}

Kim (2002) assessed the impact of lean implementation for general contractors and subcontractors along the following criteria: 1) managerial time \& attention, 2) job satisfaction, 3) turnover \& absenteeism, 4) competitiveness, 5) planning \& coordination, 6) involvement \& commitment, 7) fire-fighting, 8) productivity, 9) unplanned overtime, 10) rework, 11) resources availability, 12) working conditions, 13) wasted time, and 14) work assignments. These criteria will be used to assess the effectiveness of lean according to lean practitioners.

\subsubsection{Lean Practices}

There are a wide variety and continually increasing amount of practices and tools that a contractor can implement in their attempt to become more "lean". Based on the literature review and definitions provided by the Lean Construction Institute, twelve common lean practices were identified and defined in the survey. 


\subsubsection{Benefits}

Reported benefits of lean in extant literature relate to quality, human factors, and productivity improvements (e.g., Kung et al. 2008). These projects suggest that lean principles are effective not only in complicated processes, but also in simple processes. Yu et al. (2013) reported a case study of a U.S. modular building producer, which witnessed a $10 \%$ improvement in labor efficiency, and a production improvement of $50 \%$ within six months of implementation. Additional benefits discussed in the literature include positive environmental impacts (Ghosh et al. 2014), and potential safety improvements (Saurin et al. 2002) among others.

\subsubsection{Barriers and Challenges}

Although lean implementation has shown a number of benefits, adoption in the construction industry is still slow. McGraw Hill (2013) provided thirteen challenges to lean implementation facing contractors. These challenges include both internal and external barriers that companies have faced. The challenges identified were 1) lack of knowledge, 2) lack of industry support, 3) lack of standards, 4) lack of sufficient support from project team, 5) employee resistance, 6) inadequate commitment from top management, 7) concern regarding time required for implementation and application, 8) profitability concern, 9) union resistance, 10) lean complexity concern, 11) lack of understanding customers' needs, 12) lack of progress measurement, and finally, an 13) overall lack of supporting lean culture.

\section{METHODOLOGY}

\subsection{Survey}

Data was collected using an online survey. Survey respondents were randomly selected from the publicly available member directory of the Finishing Contractors Association (FCA). Respondents had various specialties (e.g., painting, drywall finishing, etc.) but were all involved in the finishing stage of a construction project as previously defined. The sample also represented different regions and different company sizes providing a broad view of finishing contractors in the US. The survey was sent to 300 possible respondents, from which 24 valid responses were received. Applicable questions on the survey included an "other" category to allow respondents to give additional answers.

The survey was designed to collect information from two different groups within the sample. Depending on whether or not respondents claimed to have experience with lean implementation determined which set of questions they were given. One version of the survey focused on finishing contractors currently practicing any level of lean implementation. The other had questions tailored to finishing contractors that have not implemented any specific lean practices. The self-proclaimed lean practitioners were asked:

- Background questions

- Which lean practices they had implemented

- The drivers for implementing lean

- The challenges they experienced

- The differences experienced between lean projects and traditional projects

Non-practitioner respondents were asked: 
- Background questions

- What barriers prevented them from implementing lean practices

\subsection{Limitations}

This research is limited by the relatively low response rate and the low total number of respondents. As such, it is not possible to generalize results to the industry. Additionally, since the survey was a self-report mechanism, it is possible that there may be respondents practicing lean principles that don't realize it, and conversely, respondents thinking they are practicing lean principles without actually doing it. It is also possible that respondents may have differing interpretations of the lean terms included in the survey.

\section{RESUlTS AND ANALYSIS}

\subsection{Respondent Backgrounds}

In keeping with the wider population, the majority of respondents were small contractors. $62 \%$ had less than 50 employees and almost $50 \%$ had an annual volume of less than $\$ 10$ million. Regional involvement of the respondents was heavier in the Southeast (12), but each region was represented with the Western region having the smallest representation (4). The majority of companies that self-reported as "non-practitioners" have an annual volume $<\$ 10 \mathrm{M}$, while nearly $65 \%$ of those practicing some level of lean have an annual volume $>\$ 50 \mathrm{M}$. This suggests a relationship between the scale of the contractor and awareness and implementation of lean. This is not necessarily surprising as process efficiency improvements have a greater impact over higher volumes of work.

Despite an apparent awareness of room for improvement within the finishing processes (over $90 \%$ perceived building finishing as less than efficient), only $33.3 \%$ of the survey respondents reported having implemented any of the provided lean practices. This could suggest a lack of awareness of the potential benefits of lean.

\subsection{Currently Implemented Lean Practices}

Respondents that were currently implementing some form of lean were asked to identify specific practices they had implemented. Each practice included a brief description on the survey to normalize responses. Figure 1 shows the percentage of practicing respondents that utilize each of the lean practices.

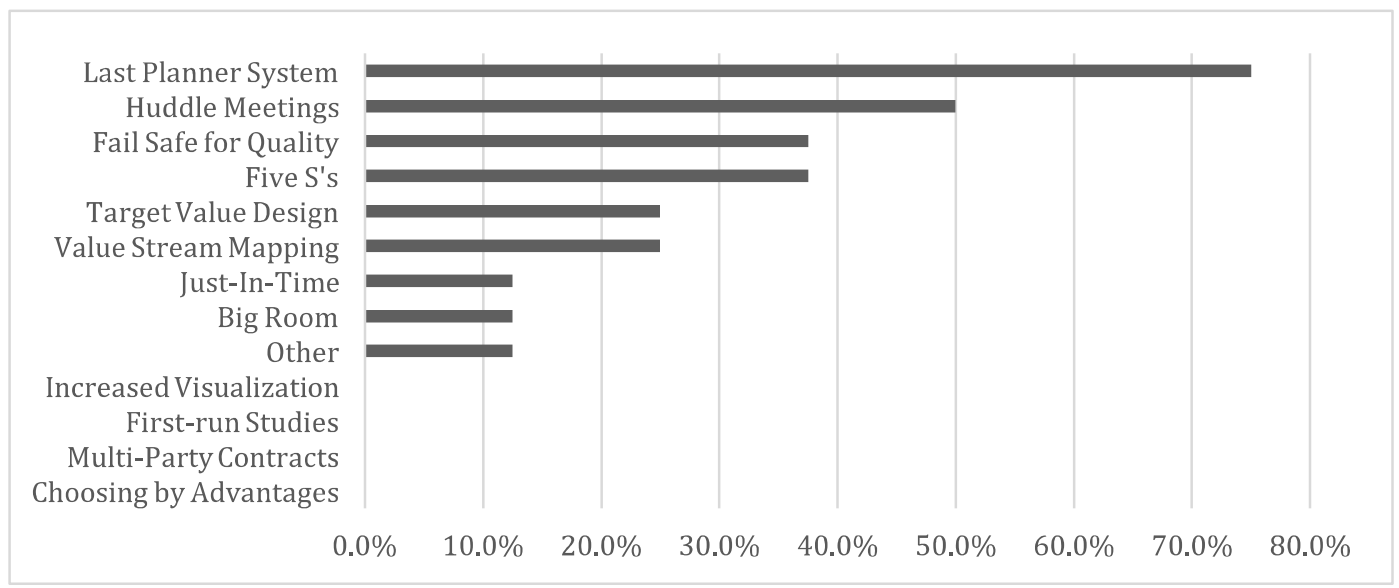

Figure 1: Lean practices currently implemented by practicing finishing contractors 
While this project did not explore details regarding the implementation of these practices, the identification of these practices can help us understand how finishing contractors are utilizing lean. The "Last Planner System"TM (LPS) was the most popular practice among the sampled finishing contractors, perhaps due to its ability to help control work flow and manage hand-offs between other trades. "Huddle meetings" support collaboration between contractors on site prior to the finishing stages, "fail-safe for quality" reduces rework and defects, and "Five S" focuses on organizing the material, and housekeeping. In the finishing phase of the project, material management is critical. "Five S" may help the contractors save time locating material and costs associated with damaged material.

\subsection{Drivers for Lean Implementation}

Practicing respondents were also asked what the primary drivers motivated them to implement lean practices. Not surprisingly, the most common driver was a desire to "improve profitability/cut costs". $100 \%$ of lean practitioners selected this as a driver for implementation. Figure 2 details the percentage of practicing respondents that were motivated to implement lean by each driver.

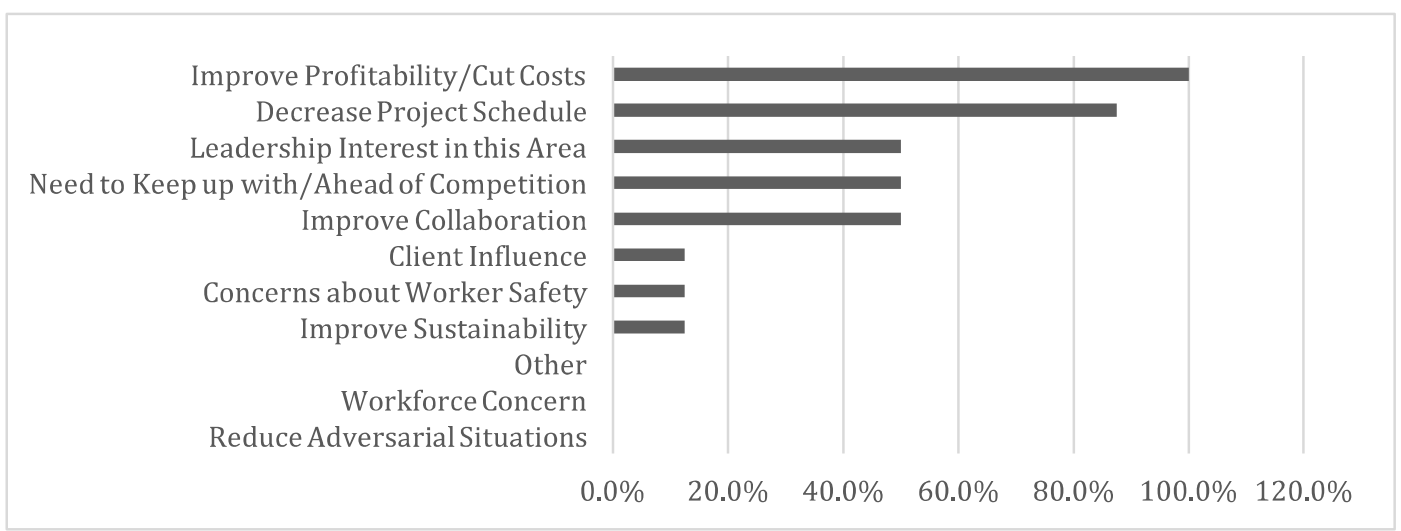

Figure 2: Drivers for lean implementation by practicing finishing contractors

The second driver to lean implementation was to "decrease project schedule". This is supported by the data in Figure 1 indicating the most commonly utilized lean practice is LPS which can decrease project schedules. As finishing contractors normally start work in the middle of the project they are heavily impacted by upstream processes and contractors. They may find lean practices such as LPS assist in making work ready to avoid wasted time and effort.

\subsection{Challenges to Lean Implementation}

The primary challenge to lean implementation for practicing finishing contractors was reported as being a "lack of knowledge" by nearly $90 \%$ of respondents. Nearly $90 \%$ of the lean practitioners experienced challenges due to a "lack of knowledge". This problem likely persists at multiple levels throughout a company - from top management to the field personnel. It may also extend to other companies they work with. The "lack of knowledge" of both internal and external participants may prevent or reduce the success of lean implementation. Figure 3 includes the percentage of practicing firms that experienced each of the challenges listed. 


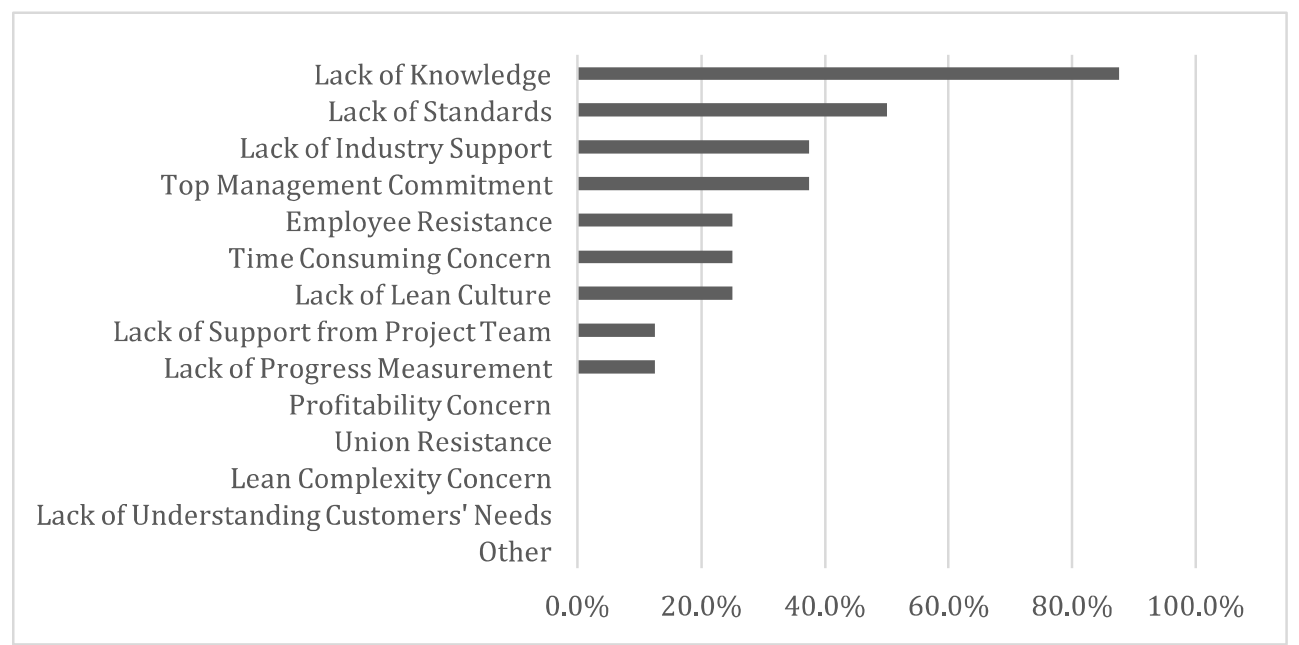

Figure 3: Lean implementation challenges for practicing finishing contractors

\subsection{Benefits of Lean Implementation}

Practicing respondents were asked to compare their experience with lean projects versus traditional projects along a number of criteria. Table 2 includes the descriptive statistics from the responses. Respondents were given a 5 -point scale where 5 indicated that the lean project was "much better" and 1 indicated that the lean project was "much worse".

Table 2: Lean implementation benefits for practicing finishing contractors

\begin{tabular}{ccc}
\hline Description & Mean & SD \\
\hline Planning and coordination & 4.50 & 0.53 \\
Client job satisfaction & 4.00 & 0.00 \\
Involvement and commitment of the contractors & 3.75 & 0.71 \\
Productivity & 3.63 & 0.52 \\
Managerial time and attention consumed & 3.50 & 0.53 \\
of trades) & 3.50 & 0.93 \\
Working conditions (overcrowded work area, crew interference and stacking & & \\
Resources availability (materials, tools, equipment and information) & 3.38 & 0.52 \\
Turnover and absenteeism & 3.13 & 0.35 \\
Number of unexpected and urgent problems experienced & 2.75 & 0.70 \\
Rework due to common problems (design changes, priority order and & 2.75 & 0.71 \\
prerequisite work) & & \\
Unplanned over time & 2.50 & 0.76 \\
Wasted time (waiting and idle time) & 2.50 & 1.07 \\
\hline (
\end{tabular}

Perhaps the most noticeable difference claimed by practitioners is in the improved "planning and coordination" experienced on lean projects $(\operatorname{avg}=4.5)$. Client job satisfaction, contractor involvement and commitment and productivity also showed 
improvement over traditional projects. On the other side, "wasted time", "rework due to common problems" and "unplanned over time" were less than traditional projects.

\subsection{Barriers to Lean Implementation}

As mentioned, $66.7 \%$ of survey respondents reported as being non-practitioners of lean. Figure 4 includes the percentage of non-practicing firms that experienced each barrier.

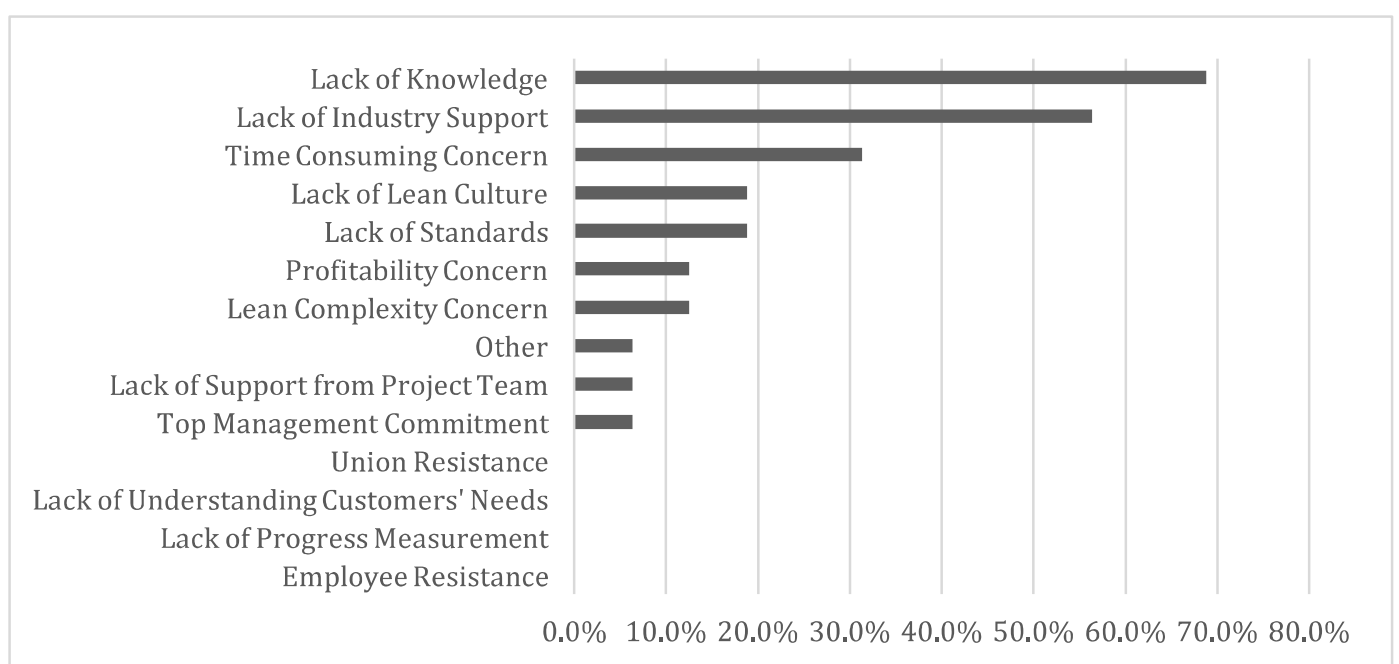

Figure 4: Barriers to lean implementation by non-practicing finishing contractors

Similar to the challenges that the lean practitioners experienced, lack of knowledge and lack of industry support are the two key barriers to implementing lean.

\section{CONCLUSION}

The survey was sent to finishing contractors in the US and their responses provide an overview of the current state of lean implementation within that specific specialty. Results include details regarding which practices are being used, what challenges and barriers are being faced, along with what benefits have resulted from implementation. The results from this study on finishing contractors are consistent with the literature regarding other trades and areas within the construction process. The data indicates that lean practices are not common among finishing contractors, especially smaller companies. Most of the finishing contractors that are implementing lean have above average annual volumes. Although lean practices show significant benefits in many aspects of the project (e.g., planning and coordination, etc.), there are still barriers that prevent finishing contractors from implementing lean (e.g., lack of knowledge, lack of support, etc.).

\subsection{Future Work and Recommendations}

In order to improve efficiency in building finishing, knowledge of lean practices needs to be more widely disseminated. A better awareness of lean practices, their benefits, challenges, and barriers could encourage specialty-wide improvements.

As the generalizability of this project data was limited by respondent number, additional data collection in the area is recommended. Perhaps more importantly, additional research on how to stimulate and support implementation by smaller contractors could also be beneficial according to the findings of this study. This could be accomplished by conducting case studies of smaller contractors that are successfully 
implementing lean practices. Improvements in this area would help a large portion of the building finishing industry take advantage of the benefits associated with lean practices.

\section{REFERENCES}

Alarcón, L.F., Diethelm, S., Rojo, O. \& Calderon, R. (2005). Assessing the Impacts of Implementing Lean Construction. In: 13th Annual Conf. of the IGLC. [online] Sydney, Australia: IGLC, pp. 387-393. Available at: http://www.iglc.net/Papers [accessed 13 Dec. 2016].

Ghosh, S., Bhattacharjee, S., Pishdad-Bozorgi, P. \& Ganapathy, R. (2014). A Case Study to Examine Environmental Benefits of Lean Construction. In: 22nd Annual Conf. of the IGLC. [online] Oslo, Norway: IGLC, pp. 133-144. Available at: http://www.iglc.net/Papers [accessed 13 Dec. 2016].

Kim, D. (2002). Exploratory study of lean construction: Assessment of lean implementation. Ph.D. University of Texas at Austin.

Koskela, L., Howell, G., Ballard, G. and Tommelein, I. (2002). The foundations of lean construction. In: Design and Construction: Building in Value. Oxford, UK: Butterworth-Heinemann, pp. 211-226.

Kung, D., Alex, D. P., Al-Hussein, M., \& Fernando, S. (2008). Application of lean thinking to improve the productivity of water and sewer service installations. Canadian J. Civ. Eng., [online] 35(4), pp. 418-430. Available at: http://www.nrcresearchpress.com/doi/pdf/10.1139/L07-136 [accessed 14 Dec. 2016]

McGraw Hill Construction (2013). Lean Construction: Leveraging Collaboration and Advanced Practices to Increase Project Efficiency. Bedford, MA. Available at: http://www.leanconstruction.org/media/docs/Lean_Construction_SMR_2013.pdf [accessed 14 Dec. 2016].

RS Means (2015). Building Construction Cost Data. RS Means Company.

Sarhan, S. \& Fox, A. (2012). Trends and Challenges to the Development of a Lean Culture Among UK Construction Organisations. In: 20th Annual Conf. of the IGLC. [online] San Diego, US: IGLC, pp. 1151-1160. Available at: http://www.iglc.net/Papers [accessed 13 Dec. 2016].

Saurin, T. A., Formoso, C. T., \& Cambraia, F. B. (2006). Towards a common language between Lean production and safety management. In: 14th Annual Conf. of the IGLC. [online] Santiago, Chile: IGLC. Available at: http://www.iglc.net/Papers [accessed 13 Dec. 2016].

Taylor, H. (2014). Cost of Constructing a Home. Special Studies, Economics and Housing Policy. Washington DC: National Association of Home Builders.

Yu, H., Al-Hussein, M., Al-Jibouri, S., \& Telyas, A. (2013). Lean transformation in a modular building company: A case for implementation. Journal of Management in Engineering, [online] 29(1), pp. 103-111. Available at: http://ascelibrary.org/doi/pdf/10.1061/(ASCE)ME.1943-5479.0000115 [accessed 14 Dec. 2016] 